\title{
BIBLIOTECA: DE FRONTEIRAS, SABERES E LIVROS
}

\author{
Maria Elisa Rodrigues Moreira \\ elisarmoreira@gmail.com
}

Resumo: A biblioteca aparece nas obras de Jorge Luis Borges e Italo Calvino como uma figura emblemática para que pensemos a literatura de ambos os escritores como espaço transdisciplinar de produção de saberes, principalmente a partir da estrutura narrativa impressa pelos autores a suas obras. Figura fronteiriça, a biblioteca se imbrica com o arquivo, a coleção, a enciclopédia e o museu, constituindo-se num lugar de saber, de memória e de deslocamento, para o qual contribuem a História, a Filosofia, a Literatura e a Comunicação.

(...) toda estante vazia é um anúncio de livros por vir. Alberto Manguel

Nas obras de Jorge Luis Borges e Italo Calvino a biblioteca aparece como uma figura emblemática, em alguns momentos por meio da constituição temática de seus textos, mas, principalmente, a partir da estrutura narrativa impressa pelos autores em suas obras, o que nos possibilita pensar sua literatura como espaço de produção de saberes. Pensar a biblioteca na obra desses autores, entretanto, exige que nos situemos na mesma posição

I Doutora em Literatura Comparada - Universidade Federal de Minas Gerais/Bolsista CNPq. 
fronteiriça em que se alocam suas produções: a biblioteca constitui-se, assim, a partir do contato com suas margens, fato que a complexifica e enriquece, instituindo-a para além de si mesma por sua imbricação com o arquivo, a coleção, a enciclopédia e o museu.

Nesse contexto, acreditamos ter na coleção um conceito chave para a reflexão acerca da biblioteca, uma vez que ela constitui-se em noção básica para a formação seja dos museus, dos arquivos ou das enciclopédias, perpassando assim a constituição das próprias bibliotecas, e funcionando como uma espécie de núcleo irradiador para esse pensamento. Entretanto, se a coleção funciona como o eixo instituidor da semelhança, seu objeto específico no caso das bibliotecas - o livro - inscreve-se como o traço de diferença que a particulariza, conforme breve apontamento de Walter Benjamin, pensador que aqui tomamos como referencial para pensar o colecionamento:

"Seria interessante estudar o colecionador de livros como o único que não necessariamente desvinculou seus tesouros de seu contexto funcional" (Benjamin, 2007, p. 24I).

Tal particularidade é também destacada por Yvette Sánchez:

"Somente o colecionamento de livros não tira os objetos de seu contexto corrente" (SÁnchEZ, I999, p. II3, tradução nossa).

É, assim, a partir desse posicionamento permeado pela semelhança e pela diferença, que procuraremos refletir acerca do conceito de biblioteca em Borges e Calvino. 


\section{A COLEÇão}

De fato, toda paixão confina com um caos, mas a de colecionar com o das lembranças.

Walter Benjamin

Os estudos sobre o colecionamento nos permitem identificar diversos aspectos característicos da coleção, sobre os quais poderíamos centrar nossas reflexões a respeito da biblioteca, como a relação entre conhecimento e coleção; o aspecto de conjunto da coleção e sua potencialidade narrativa; a constituição da coleção através da posse e da atribuição de valor; seu caráter (auto)biográfico; sua tentativa de ordenar o mundo; sua constituição como lugar de memória... Nesse momento, entretanto, procuraremos delinear nossa ideia de coleção a partir de dois elementos do que consideramos seu núcleo central: sua origem etimológica e sua motivação.

Yvette Sánchez aponta duas aproximações etimológicas da coleção: primeiramente, a partir do latim collectio, ela se conforma como a ação de juntar, de reunir, de coletar objetos, e é nessa noção de conjunto de coisas agrupadas que encontramos um de seus aspectos primordiais; em outra perspectiva, do grego legein derivam-se tanto o ato de ler quanto o de colecionar, de onde a autora afirma "a escritura como coleção" e que "ler é colecionar" (SÁNCHEZ, I999, p. II), aspecto fundamental para o pensamento acerca da biblioteca que intentamos desenvolver.

Essa aproximação entre coleção e leitura é também apontada por Christian Jacob (2008b) quando o pesquisador trata da constituição da Biblioteca de Alexandria e das atividades intelectuais dela decorrentes: formar as coleções da biblioteca é, ao menos como projeto, um trabalho de acumulação de todo o saber escrito existente no mundo até então, num processo que implica leituras prévias e que possibilitará uma série de posteriores leituras e escritas. "Ler para escrever", frase que dá título a seu 
texto, seria a forma constitutiva dos processos intelectuais e cognitivos desenvolvidos pelos alexandrinos a partir de sua biblioteca, e acreditamos que também das literaturas de Jorge Luis Borges e Italo Calvino.

Decorrente de sua primeira acepção etimológica, concebemos uma coleção, normalmente, como um agrupamento de coisas que pertencem a uma mesma classe e estão organizadas segundo uma determinada norma, formando um todo coerente e coeso, ainda que os elementos que a componham mantenham sua individualidade. Esse agrupamento seria motivado, para retomarmos uma expressão de Walter Benjamin, por uma "luta contra a dispersão":

Talvez o motivo mais recôndito do colecionador possa ser circunscrito da seguinte forma: ele empreende a luta contra a dispersão. O grande colecionador é tocado bem na origem pela confusão, pela dispersão em que se encontram as coisas no mundo. (...) O colecionador (...) reúne as coisas que são afins; consegue, deste modo, informar a respeito das coisas por meio de suas afinidades ou de sua sucessão no tempo. (Benjamin, 2007, p. 245)

É a partir de uma visita a uma "exposição de coleções estranhas" em Paris, que Italo Calvino vai tecer uma reflexão sobre o colecionamento, em especial pela observação de uma coleção de areia:

Tem-se a impressão de que essa amostragem da Waste Land Universal esteja para nos revelar alguma coisa importante: uma descrição do mundo? Um diário secreto do colecionador? Ou um oráculo sobre mim, que estou a escrutar nestas ampulhetas imóveis minha hora de chegada? Tudo isso junto, talvez. (...)

É que, como toda coleção, esta também é um diário: diário de viagens, claro, mas também diário de sentimentos, de estados de ânimo, de humores (...). Ou talvez apenas diário daquela obscura agitação que leva tanto a reunir uma coleção quanto a manter um diário, isto é, a necessidade de transformar o escorrer da própria existência numa série de objetos salvos da dispersão, ou numa série de 
linhas escritas, cristalizadas fora do fluxo continuo dos pensamentos. (Calvino, 2orob, p. г2-13)

Nesta breve reflexão decorrente da observação da areia colecionada, Calvino aponta várias questões relativas ao colecionamento, dentre as quais nos interessa destacar o aspecto da motivação do colecionador e sua relação com a leitura/escrita: colecionar é uma necessidade de "luta contra a dispersão" tão grande quanto o é a escrita, uma necessidade de fixar e ordenar o fluxo caótico do mundo numa folha de papel, nas páginas de um livro, na narrativa infindável de uma imensa e babélica biblioteca.

Calvino indica assim que colecionar o próprio pensamento, circunscrevendo-o nos limites da palavra escrita, pode ser uma forma de lutar contra o caos de informações do mundo. Seria essa uma forma de reagir à perspectiva de uma memória infindável como a de Irineo Funes, capaz de rememorar e recordar cada instante e cada situação, objeto, sentimento do mundo, mas incapaz de produzir um pensamento próprio? (Borges, 2007a)

Ao escolher e recolher o que se deseja ver preservado e reunido numa coleção, o homem não estaria praticando o esquecimento do que opta por deixar de fora, por não coletar? Colecionar, lutar contra a dispersão não seria também uma forma de distinguir o que deve ser lembrado e o que deve ser esquecido? Afinal, "colecionar é uma forma de recordação prática" (BENJAMIN, 2007, p. 239) e "o esquecimento permite, muitas vezes, sobreviver. Se nós lembrássemos tudo, não conseguiríamos viver." (SERRES, 2007, p. 164)

Ao constituir suas narrativas, Borges e Calvino estariam fazendo de suas obras coleções de pensamentos e saberes nas quais o mundo, o conhecimento, a literatura se apresentam sob uma nova organização, preservados da dispersão que os cerca e a salvo de perder-se no "monte de lixo" que pode tornar-se a memória humana que procura dar conta de tudo simultaneamente. Ao colecionarem suas leituras e saberes e ordenarem 
essas coleções por meio de um novo texto, de uma literatura que dialoga com tempo e espaço e reinscreve sua memória num texto outro, Borges e Calvino fazem de suas obras bibliotecas, coleções de livros, arquivo de saberes políticos, científicos e estéticos que desejam ver preservados.

\section{A biblioteca, COLEÇão de LiVRos}

(...) A biblioteca gera diálogos diferidos, reiterados e impossiveis. Ela permite justapor ideias, fatos e informaçôes formulados outrora por autores diferentes, separados no espaço e no tempo.

Christian Jacob

Se a biblioteca pode ser pensada como um tipo de coleção, configurado pelas linhas gerais que norteiam os estudos do colecionamento, seu traço de diferença nesse conjunto irá inscrever-se especialmente a partir da questão da utilidade. Conforme Benjamin (2007), um dos elementos identificadores das coleções é a retirada de seus objetos de suas relações primeiras e, com isso, seu deslocamento e a abolição de sua funcionalidade:

É decisivo na arte de colecionar que o objeto seja desligado de todas as suas funções primitivas, a fim de travar a relação mais intima que se pode imaginar com aquilo que lhe é semelhante. Essa relação é diametralmente oposta à utilidade e situa-se sob a categoria singular da completude. (Benjamin, 2007, p. 239)

Esta característica, no entanto, não se aplicaria à coleção de livros, como vimos na questão por ele levantada e que reproduzimos no início deste texto: a coleção de livros diferencia-se das demais justamente por nela não haver uma desvinculação de seu valor de uso. 
A biblioteca, assim, seria uma coleção na qual os objetos mantêm sua funcionalidade original. Talvez por essa particularidade Phillip Blom afirme que

Colecionar livros é uma atividade multifacetada. Talvez seja a forma mais rica e ambigua de colecionar. (...) Em nenbum outro lugar o ato de colecionar tem faces mais diversas do que entre aqueles que investem seu capital, temporal e financeiro, em livros (BLOM, 2003, p. 228-229).

Acreditamos, inclusive, que ao compor uma coleção, ao constituir uma biblioteca, o livro não apenas conserva seu valor de uso, mas o tem amplificado por sua inserção no conjunto.

Dessa forma, a biblioteca e seus objetos, os livros, se tornam imagens emblemáticas para se pensar a produção de conhecimentos, uma vez que se apresentam como uma imensa base de saberes disponíveis à leitura, à interpretação e à expansão. Walter Benjamin afirma que "colecionar é um fenômeno primevo do estudo: o estudante coleciona saber" (Benjamin, 2007, p. 245), hipótese que reverbera na reflexão de Sánchez sobre a leitura e a escritura como coleção: "o saber escrito se organiza em coleções de livros” (SÁnchez, I999, p. IoI, tradução da autora).

A produção de saberes a partir de uma coleção de livros deriva assim, justamente, da potencialização de seu valor de uso ao ser inserido num conjunto mais amplo de conhecimentos passíveis de se intercambiarem. Ela está intrinsecamente vinculada à poética do colecionamento traçada por Sánchez, marcada pela concepção de que ler é colecionar e de que a escritura é uma coleção. A escritura se faz, assim, a partir de uma coleção de leituras, através da qual a memória aproxima o mesmo e o outro, num movimento de ressignificação constante.

Retomando o próprio Benjamin e seu hábito constante de tomar notas das mais diversas referências em uma caderneta, a autora indica: 
O trabalho principal consistia em tirar estes fragmentos de seu contexto e dispô-los de uma forma nova, arbitrária e nunca definitiva, de tal maneira que se iluminariam mutuamente. Com este tipo de montagem indagava os rumores da tradição, sem dar ares de vidente ou inovador; Hannah Arendt o compara com o trabalho do mergulhador de pérolas, cuja tarefa consiste em tirar das profundezas do mar - do passado - e transportar para a superfície (para a memória) fragmentos preciosos de pensamentos díspares, criando a nova totalidade. Coleciona lendo. Conserva e destrói ao mesmo tempo. (SÁnCHEZ, I999, p. II8, tradução da autora)

Vinculando esse pensamento acerca da coleção de livros, da biblioteca, à literatura, em especial às obras de Jorge Luis Borges e Italo Calvino, encontramo-nos diante de autores que fazem da leitura seu processo de escrita: o escritor parte de sua coleção de leituras para produzir seu próprio texto, numa relação que mescla memória e criação, conservação e destruição. Colecionar é, assim, ler, embaralhar e fazer colidir os diversos textos que se encontram à deriva e, no processo da escritura, ressignificá-los, deslocá-los, "reterritorializá-los". Conforme Sánchez (I999, p. 256), "escrever significa incorporar o lido, quer dizer, os textos anteriores colecionados, em outro texto novo".

\section{As Bibliotecas de borges e CALVINO}

Todos os livros que li formam em mim uma biblioteca. Não, porém, bem ordenada, os volumes não estão em ordem alfabética, não existe catálogo. E, todavia, é exatamente assim, uma memória na qual se acumulam as minhas leituras.

Roland Barthes e Antoine Compagnon

A partir do exposto, é possível pensarmos as obras de Borges e Calvino como tendo sido elaboradas com base num projeto de biblioteca, como 
uma literatura que tem a biblioteca por metáfora e modelo literário e que se constitui por meio de um trabalho de espessamento dos limites e reafirmação da fronteira como espaço de produção dos saberes. A biblioteca funciona, assim, como topos do diálogo entre os mais diversos conhecimentos, temporalidades, espacialidades e formas textuais, e é em suas brechas e deslindes que irá se produzir um saber outro, um saber narrativo poroso, aberto, interminavelmente conectável:

Um livro é escrito para que possa ser posto ao lado de outros livros, para que entre numa prateleira hipotética e, ao entrar nela, de alguma maneira a modifique, expulse dali outros volumes ou os faça retroceder para a segunda fileira e reclame que se coloquem na primeira fileira outros livros. (CALvino, 2009, p. I90)

Ao longo do tempo, nossa memória vai formando uma biblioteca díspar, feita de livros, ou de páginas, cuja leitura foi para nós uma felicidade e que gostariamos de compartilhar. (...) Não sei se sou um bom escritor; creio ser um excelente leitor ou, em todo o caso, um sensivel e grato leitor. Desejo que esta biblioteca seja tão diversa como a não saciada curiosidade que me induziu, e continua a induzir-me, à exploração de tantas linguagens e tantas literaturas. (BoRGEs, I999, p. 5I9)

Esse diálogo com uma memória escrita inesgotável, com uma biblioteca desejosa de abarcar "todos os escritos da Terra" (JACOB, 2008b, p. 45) transparece na mobilidade e multiplicidade do universo poético dos dois autores, que transitam entre temáticas e estilos narrativos diversificados, mesclados em produções narrativas, poéticas e ensaísticas que se mostram confluentes e coerentes ao desbordar as fronteiras dos gêneros discursivos e ao fazer transitar dúvidas, hipóteses e saberes múltiplos. Crítica e ficção andam juntas e se interpolam na tessitura de narrativas que são, permanente e simultaneamente, uma forma de reflexão.

Um voraz apetite pela leitura é perceptível nas produções de Borges e Calvino, fazendo delas vastas bibliotecas, territórios livrescos em que 
a tradição é rememorada e recriada constantemente; em que o sonho, a realidade e a imaginação se imbricam de forma contínua; e em que o saber constrói-se a partir do diálogo entre a ficção e a reflexão em suas mais variadas formas de aparição. ${ }^{2} \mathrm{Na}$ construção de suas poéticas, Borges e Calvino têm na biblioteca não apenas um objeto e uma temática, mas também uma estratégia narrativa: eles criam seus textos como se compusessem uma biblioteca na qual os mais diversos textos confrontam-se para o estabelecimento de um texto que os releia e os rediga. A biblioteca funciona, assim, como uma coleção de textos temporal e espacialmente deslocados e reorganizados por Borges e Calvino numa outra narrativa, como procuraremos brevemente apresentar a seguir.

Para aprofundarmos um pouco mais nossa reflexão sobre a biblioteca em Borges, procuremos fugir da sombra da Biblioteca de Babel (Borges, 2007 b) e de sua metaforização do infinito, da imensidão, do buraco negro que paira sobre a ideia de uma coleção de livros. Naveguemos pela obra borgeana por meio de um livro menos emblemático, mas nem por isso distante desse labirinto evocado por Babel: O livro dos seres imaginários (Borges e Guerrero, 2007). Escrito com a colaboração de Margarita Guerrero, esse livro aparece em 1967 como uma "segunda versão ampliada" do Manual de Zoología Fantástica (Borges e Guerrero, 20oi), livro que havia sido publicado dez anos antes.

Normalmente estudado como um bestiário de seres reais e imaginários, acreditamos que $O$ livro dos seres imaginários pode ser lido por outro ângulo, como uma grande compilação de antigos livros e fábulas, uma coleção de textos acerca dos animais, enfim, uma biblioteca do que os autores denominam "seres imaginários". Seu vínculo com a ficção desenha-

2 É interessante, nesse aspecto, observarmos como expressões relativas a outros textos são constantes em suas obras e nas obras a seu respeito - como "os livros dos outros", em Calvino, e "os livros alheios" em Borges. 
-se ainda no prólogo, ${ }^{3}$ quando Borges e Guerrero procuram estabelecer os limites do que estaria contido no termo "seres imaginários": "um manual dos estranhos entes engendrados, ao longo do tempo e do espaço, pela fantasia dos homens" (Borges e Guerrero, 2007, p. 9). O livro dedica-se, portanto, a ficções, a seres forjados pelo homem ao longo do tempo, a leituras rememoradas de outros textos, aqui compilados.

E, ainda no prólogo, afirma-se também a questão da incompletude inerente a qualquer projeto de biblioteca, como havíamos já observado em relação à "Biblioteca de Babel": "um livro dessa índole é necessariamente incompleto; cada nova edição é o núcleo de edições futuras, que podem multiplicar-se ao infinito" (Borges e Guerrero, 2007, p. 9). Se, em Babel, é a biblioteca que se multiplica ao infinito num jogo de espelhos, aqui o próprio livro é pensado como um desdobramento interminável de referências. ${ }^{4}$

Composto por verbetes alfabeticamente ordenados, O livro dos seres imaginários traz à luz, em suas páginas, animais derivados de textos das mais diversas origens temporais e espaciais. Excertos de Franz Kafka, C. S. Lewis, Edgar Allan Poe, Wang Ta-hai e William T. Cox, por exemplo, aparecem como transcrições, compondo verbetes cujos textos integrais são citados entre aspas. Ao lado deles, referências inesgotáveis compõem os demais verbetes: a tradução de Richard Burton para As mil e uma noites e a História Natural de Plínio, o Velho convivem amistosamente com obras como as Cartas edificantes e curiosas do padre Zallinger ou o Bundahish. ${ }^{5}$ Para a composição dos seres de alguns verbetes, como é o caso

3 Sobre a utilização deslocada que Borges faz dos elementos que normalmente tendem a orientar a leitura, ver NAScimento, 2007.

4 A imagem de um livro infinito, que se desdobra em outros inumeráveis, é explorada ao limite por Borges em "O livro de areia" (Borges, 2009).

5 Vale lembrar que, aqui, não nos interessamos em investigar a "fidedignidade" das fontes indicadas por Borges, conhecido por suas atribuições errôneas ou referência a obras inexistentes. Acreditamos que o que merece atenção é o efeito dessa escolha 
da fênix, as referências a outros textos multiplicam-se: encontram-se ali citadas as mitologias egípcia, grega e romana; Tácito; Plínio, o Velho; Heródoto; Claudiano; Ovídio; Dante; Shakespeare; Pellicer; Quevedo; Milton; Lactâncio; Tertuliano; Santo Ambrósio; Cirilo de Jerusalém...

Esses breves exemplos procuram indicar uma possível leitura de $O$ livro dos seres imaginários como uma grande biblioteca acerca dos animais e outros seres engendrados pela imaginação humana ao longo do tempo e nos mais diversos lugares. A estratégia narrativa de Borges assemelha-se, aqui, a uma prática corrente apontada por Jacob (2008b) relativamente aos estudiosos da Biblioteca de Alexandria, que a partir da biblioteca compunham “(...) as coleções de palavras raras, de curiosidades naturais, culturais, lexicais ou semânticas colhidas ao longo dos textos antigos, que podem ser redistribuídas em novos textos, em ordem alfabética e/ ou temática, ou conforme as regiões geográficas e os diferentes dialetos" (JACOB, 2008b, p. 65). Dentre essas “compilações”, ele cita: Das palavras suspeitas de não terem sido usadas pelos antigos, Da denominação das idades (dos homens, das mulheres, dos animais domésticos, dos animais selvagens, das aves...), Dos nomes de parentesco, Expressões áticas, Glosas lacônias, Provérbios não métricos, Provérbios métricos, Coleção das maravilhas de toda a Terra, classificada por lugares... Não nos causaria estranhamento se, ao longo dessa lista, encontrássemos $O$ livro dos seres imaginários.

Italo Calvino também nos apresenta numerosos textos nos quais podemos apontar de forma bastante contundente a biblioteca como eixo constituinte da narrativa, como é o caso do também emblemático romance Se um viajante numa noite de inverno (1999), no qual Calvino narra o percurso do Leitor, protagonista da obra, na tentativa de leitura de um determinado livro, numa jornada sem fim que o leva a outro livro, e a outro livro, e a outro livro... Encontramo-nos em uma biblioteca na

narrativa, que transfere a um outro texto a origem da informação por ele apresentada, remetendo sempre a outras leituras, sejam elas reais ou fictícias. 
qual técnicas narrativas, estilos literários, discussões críticas e teóricas vão constantemente direcionando e modificando uns aos outros. Ou em $O$ castelo dos destinos cruzados (1994), no qual diversas pequenas narrativas - nas quais identificamos os personagens de Hamlet, Rei Lear, Macbeth, Orlando, Jocasta, Édipo, Parsifal, Merlin, Robinson Crusoé, Fausto, entre outros - são construídas por personagens mudos através das cartas de um baralho de tarô.

Mas procuremos também percorrer a biblioteca na obra de Calvino por uma via menos explorada nesse aspecto: As cidades invisiveis (2004). É possível pensar esse apropriar-se da palavra alheia, dessa coleção de informações, objetos, livros, dessa leitura do mundo, a partir da própria estrutura narrativa desse livro. Nele, o viajante veneziano Marco Polo narra suas viagens e apresenta as cidades que conheceu para Kublai Khan, o imperador mongol a quem serviu durante vários anos. Por meio de uma série de curtos textos, o escritor nos coloca diante de um mapa fictício, no qual as cidades funcionam como mote para as discussões entre Khan e Polo, nas quais se discorre sobre Filosofia, ciência, linguagem, representação, História, memória... Seria possível, dessa maneira, pensar As cidades invisiveis como uma coleção de verbetes de uma vasta enciclopédia, repleta de entradas distintas e de percursos de leitura que podem compor um saber múltiplo e variável conforme os trajetos seguidos, entradas essas que se iluminam e obscurecem simultaneamente; como uma coleção de relatos em que memória, conhecimento e ordenação do mundo são colocados em diálogo através da narrativa ficcional; como uma biblioteca particular de saberes diversificados.

Calvino recorre a leituras diversas para compor sua narrativa, trazendo para o centro da ficção personagens históricas - como Kublai Khan e Marco Polo - e literárias - como não pensar nas mil e uma histórias de Sheherazade... -, além de reflexões advindas das mais diversas áreas do conhecimento. Não é sem motivo que, a respeito desse livro, Calvino afirma acreditar ser a obra na qual pensa "haver dito mais coisas", talvez 
por ter "conseguido concentrar em um único símbolo todas as minhas reflexões, experiências e conjecturas" (CALvino, I995, p. 85), ao que poderíamos acrescentar todas as leituras colecionadas ao longo de sua vida, toda sua biblioteca - ainda que, nesse texto, Calvino não explicite a origem dessas leituras, como o faz Borges em O livro dos seres imaginários.

Como "toda estante vazia é um anúncio de livros por vir" (Manguel, 2006, p. 75), pensar a biblioteca como um modelo possível de produção de conhecimento é também pensar o saber como um processo contínuo e infindável, múltiplo e dinâmico. Conforme afirma Jacob (2008a, p. ro), ainda que a biblioteca seja uma instituição, um espaço físico, ela "é também, e simultaneamente, um desígnio intelectual, um projeto, um conceito imaterial que dá sentido e profundidade às práticas de leitura, de escrita e de interpretação. Enfim, é uma coleção de livros, o efeito resultante de sua justaposição e interação (...)”. Assim como nenhuma biblioteca um dia será total, por mais que os fantasmas de Babel e Alexandria a habitem, a produção de um saber narrativo nunca será também completa e unívoca: através da narrativa é possível a construção de um saber que agrega em si a diversidade e se produz numa zona fronteiriça que ele mesmo constantemente desloca e altera, um saber marcado pela mudança e pela transitoriedade, enfim, pelo que Italo Calvino chama de incapacidade de concluir.

\section{REFERÊNCIAS}

Benjamin, Walter. Desempacotando minha biblioteca. Um discurso sobre o colecionador. In: Benjamin, Walter. Rua de mão única. Obras escolhidas. V. II. São Paulo: Brasiliense, 2000. p. 227-235.

Benjamin, Walter. O colecionador. In: Benjamin, Walter. Passagens. Belo Horizonte: Ed. ufmG; São Paulo: Imprensa Oficial do Estado de São Paulo, 2007. p. 237-246. 
BLom, Philipp. Ter e manter: uma história íntima de colecionadores e coleções. Rio de Janeiro: Record, 2003.

Borges, Jorge Luis. Biblioteca pessoal: prólogos. In: Borges, Jorge Luis. Obras completas. São Paulo: Globo, I999. v. 4. p. 515-627.

. Funes, o memorioso. In: Borges, Jorge Luis. Fiç̧ões. São Paulo: Companhia das Letras, 2007a. p. 99-108.

. A biblioteca de Babel. In: Borges, Jorge Luis. Fiç̧ôes. São Paulo: Companhia das Letras, 2007b. p. 69-79.

. O livro de areia. In: Borges, Jorge Luis. O livro de areia. São Paulo: Companhia das Letras, 2009. p. I00-105.

Borges, Jorge Luis; Guerrero, Margarita. Manual de zoología fantástica. México: Fondo de cultura Económica, 200I.

Borges, Jorge Luis; Guerrero, Margarita. O livro dos seres imaginários. São Paulo: Companhia das Letras, 2007.

Calvino, Italo. O castelo dos destinos cruzados. São Paulo: Companhia das Letras, 1994.

. Seis propostas para o próximo milênio. 2. ed. São Paulo: Companhia das Letras, I995.

. Se um viajante numa noite de inverno. São Paulo: Companhia das Letras, I999.

Collezione di sabbia. In: Calvino, Italo. Colezzione di sabbia. Milano: Mondadori, 2002. p. 5-10.

. As cidades invisiveis. 2. ed. São Paulo: Companhia das Letras, 2004. . Para quem se escreve? (A prateleira hipotética). In: CAlvino, Ita1o. Assunto encerrado: discurso sobre literatura e sociedade. São Paulo: Companhia das Letras, 2009. p. 190-195.

Canfora, Luciano. Livro e liberdade. Rio de Janeiro: Casa da Palavra/ Ateliê Editoria, 2003. 
Cоцомво, Fausto. Os arquivos imperfeitos: memória social e cultura eletrônica. São Paulo: Perspectiva, I991.

Compagnon, Antoine. O trabalho da citação. Belo Horizonte: Ed. ufmg, 2007 .

Foucault, Michel. As palavras e as coisas: uma arqueologia das ciências humanas. 8. ed. São Paulo: Martins Fontes, 2002.

Jaсов, Christian. Prefácio. In: Baratin, Marc; Jaсob, Christian. O poder das bibliotecas: a memória dos livros no Ocidente. 3. ed. Rio de Janeiro: Ed. UFRJ, 2008a. p. 9-I7.

Ler para escrever: navegações alexandrinas. In: Baratin, Marc; Jасов, Christian. O poder das bibliotecas: a memória dos livros no Ocidente. 3. ed. Rio de Janeiro: Ed. UfrJ, 2008b. p. 45-73.

Manguel, Alberto. A biblioteca à noite. São Paulo: Companhia das Letras, 2006.

Marques, Reinaldo Martiniano. O arquivo literário como figura epistemológica. Matraga, Rio de Janeiro, v. I4, n. 2I, p. I3-23, jul./dez.2007.

Nascimento, Lyslei. Monstros no arquivo: esboço para uma teoria borgiana dos monstros. In: JeHA, Julio (Org.). Monstros e monstruosidades na literatura. Belo Horizonte: Ed. UfMG, 2007. p. 6I-80.

Sánchez, Yvette. Coleccionismo y literatura. Madrid: Cátedra, I999.

Serres, Michel. Júlio Verne: a ciência e o homem contemporâneo. Rio de Janeiro: Bertrand Brasil, 2007.

Aвstract: The library appears in the works of Jorge Luis Borges and Italo Calvino as a key figure to think the literature of both writers as transdisciplinary space of knowledge production, especially from the narrative structure printed by the authors in their works. Border figure, the library is mixed with the file, the collection, the encyclopedia and the museum, establishing itself as a place of 
learning, memory and displacement, in which contributes to the history, philosophy, literature and communication.

KEYwORDS: library; collection; narrative knowledge; Jorge Luis Borges; Italo Calvino 